This "frictional welding" theory does not explain, however, the low value of the power necessary to reduce the static friction completely, and the fact that, as the exciting transducer current is increased, a highly polished steel block has a tendency to creep along a horizontal plane, and even climb uphill on an inclined plane, thus yielding in the latter case what would be called effectively a negative value of the coefficient of static friction (Fig. 4). It can be well imagined that the forces generated by the vibrations themselves are sufficient to "float" the sliding block and support its weight. However, a mere support or weakening of the friction-welded junction does not necessarily imply a forward motion. A better explanation is suggested by the newly developed concept of acoustic streaming. It has been shown analytically ${ }^{11}$ that when the second order terms of the general wave equation are considered, the stationary wave equation for a fluid between parallel walls has an added static term. This implies that although a standing wave pattern is not considered to move in a forward direction, yet it does have a component that displaces itself along the boundaries. Thus, the sliding block of highly polished steel can ride the wave front of any forward wave motion that exists along a boundary.

\section{ACKNOWLEDGMENT}

'The authors wish to thank Harvey A. Miller for many helpful discussions during the course of this investigation.

${ }^{11}$ W. L. Nyborg, J. Acoust. Soc. Am. 30, 329 (1958).

JOURNAL OF APPLIED PHYSICS

VOLUME 30, NUMBER 10

OCTOBER, 1959

\title{
Characteristics of $\mathrm{UC}, \mathrm{ZrC}$, and $(\mathrm{ZrC})(\mathrm{UC})$ as Thermionic Emitters* ${ }^{*}$
}

\author{
R. W. PIDD, $\ddagger$ Randall Laboratory of Physics, University of Michigan, Ann Arbor, Michigan
}

AND

G. M. Grover, D. J. Roehling, E. W. Salmi, J. D. Farr, N. H. Krikorian, and W. G. Witteman Los Alamos Scienlific Laboratory, Los Alamos, New Mexico

(Received February 3, 1959)

\begin{abstract}
Uranium carbide is found to have the property of high thermionic emission in the observed temperature range from 1400 to $1800^{\circ} \mathrm{K}$. The parameters of the Richardson equation which can be used to fit the data are $A=7.3 \times 10^{5} \mathrm{amp} / \mathrm{cm}^{2}\left({ }^{\circ} \mathrm{K}\right)^{2}$ and $\phi=4.57 \mathrm{v}$. While these parameters accurately predict the observed saturated currents, it is doubtful that such anomalous values are of theoretical significance within the framework of the Richardson-Dushman derivation. A solid solution form of uranium carbide and zirconium carbide gives substantially the same thermionic emission as uranium carbide, and for other reasons appears to be the more useful emitter. The carbides require no surface preparation or activation schedule for use as emitters.
\end{abstract}

\section{INTRODUCTION}

$I^{\mathrm{N}}$ $\mathrm{N}$ the course of studies on the plasma thermocouple, ${ }^{1}$ a search was instigated for high temperature emitters which could withstand the presence of a cesium atmosphere. A previous report ${ }^{2}$ had shown that several carbides, including zirconium carbide, have excellent emission properties. Following this guide, we have found that uranium carbide is an exceptionally good emitter. To our knowledge, the thermal emission characteristics of uranium carbide have not been previously

\footnotetext{
* This work was supported by the U. S. Atomic Energy Commission.

$\dagger$ Study of the solid solution forms of the carbides was suggested to us originally by $B$. Matthias in private consultation.

¥Consultant to Los Alamos during this research program. Present address: John Jay Hopkins Laboratory for Pure and Applied Science, General Atomic Division of General Dynamics Corporation, San Diego, California.

1 Grover, Roehling, Salmi, and Pidd, J. Appl. Phys. 29, 1611 (1958).

${ }_{2}^{2}$ D. L. Goldwater and R. E. Haddad, J. Appl. Phys. 22, 70 (1951).
}

reported. It has also been found that the polycarbide, $\mathrm{ZrC}: \mathrm{UC}$, has emission characteristics comparable with $\mathrm{UC}$, and that the polycarbide has further advantages in respect to practical use. Compatibility of the UC and $\mathrm{ZrC}$ with cesium vapor has also been demonstrated, but the work reported here refers only to performance in vacuum. These emission studies are exploratory in nature and they are quite incomplete. However, the results appear to be sufficiently promising to make publication worthwhile at this time.

\section{PREPARATION}

Physical form and chemical purity are often crucial determinants of emission properties. As to physical form, the carbide emitters have been made by melting small ingots in a rare gas arc, and allowing them to solidify on a suitable metallic base. The melts, so formed, are solid, and are of a silvery, metallic appearance. Macroscopic crystalline patterns are usually seen in the surface. The ingots were prepared in CMB 
Division at Los Alamos. Following is a record of the carbide preparation.

Materials.- The uranium metal had its surface layer of oxide removed by immersing it in dilute nitric acid. The cleaned metal was then subjected to a preliminary arc melting for outgassing and removal of any volatile impurities.

The zirconium metal sponge was also arc melted first to clean it up.

The graphite (AUC grade) was outgassed in vacuo at $2000^{\circ} \mathrm{C}$, before use.

Apparatus.-The arc furnace was of water cooled copper construction. It had a moveable cathode with a tungsten tip. Pickup of either copper or tungsten by the sample was found to be negligible. The furnace could be evacuated by an oil diffusion pump backed by a mechanical pump to approximately $10^{-5} \mathrm{~mm} \mathrm{Hg}$. The power supply was a $34.5 \mathrm{kw}$ welding generator of the rectifier type. A high-frequency unit was used to initiate the arc in argon.

Procedure.-The carbide was prepared by placing the metal and the required amount of graphite on the copper hearth. The system, after evacuation, was filled with tank argon to a pressure of 8 to $10 \mathrm{~cm}$ below atmospheric. The argon in the furnace was "gettered" by melting a zirconium button with the arc. After the carbide had been formed the arc was turned off and this button was flipped over on the hearth by means of the moveable cathode without opening the furnace to the atmosphere. What had previously been the bottom side of the button was now melted. This procedure was repeated until the carbide had been melted on both sides a total of three times.

For the preparation of solid solutions by arc melting the necessary amounts of uranium monocarbide and zirconium carbide were placed on the hearth as above. Upon heating these the UC melted first and wet the $\mathrm{ZrC}$. The temperature was then raised to melt the entire sample. These buttons were also turned over to attain homogeneity.

It was found possible to form rough rods of the carbides by placing pieces of the carbide in a narrow trough cut in the copper hearth and melting them in this. However, it was observed that the solid solution $\mathrm{ZrC}$ : UC was too brittle for this operation. Consequently powder metallurgy techniques were used for forming this into shapes as follows. The $\mathrm{ZrC}$ : UC powder $(-140 \mathrm{mesh})$ was mixed with $5 \mathrm{wt} \%$ of cobalt powder ( -325 mesh).

The mixture was hot-pressed in vacuum in graphite dies heated inductively. The pressing conditions were $3000 \mathrm{psig}$ at approximately $1900^{\circ} \mathrm{C}$. To remove the cobalt, the piece was heated in vacuum to around $2000^{\circ} \mathrm{C}$ in a concentrator.

A solid solution, $\mathrm{ZrC}$ : UC, was also prepared without cobalt by mixing the two carbide powders and heating them for $4 \mathrm{hr}$ at $2000^{\circ} \mathrm{C}$ in an inductively heated graphite crucible. This resulted in a sintered rod of solid solution which could be handled.

\section{EMISSION APPARATUS}

Saturated emission currents were measured by constructing an elementary vacuum diode. Size and form of the emitter and backing were dictated by the plasma cell construction, for all emitters were intended for direct trial in the cell. ${ }^{1} \mathrm{~A}$ drawing of the vacuum apparatus is shown in Fig. 1. The emitter is a plane tantalum disk, $\frac{5}{8}$ in. diam and $\frac{1}{8}$ in. thick, coated with a melted carbide about $\frac{1}{32}$ in. thick. The disk is heated by electron bombardment against the reverse side of the disk. The electron gun capacity is $3 \mathrm{kv}$ and $1 \mathrm{amp}$ maximum, allowing us to reach the melting temperature of any of the samples used. Opposite the emitter surface is a disk collector of the same diameter as the emitter, surrounded by a ring in the same plane, so as to provide a nearly uniform field for electron acceleration. The guard ring is directly grounded. The collector is grounded through an ammeter. By changing the potential of the emitter disk relative to ground, accelerating potential differences as high as $3 \mathrm{kv}$ can be established between emitter and collector electrodes. In this way the emission can be saturated, and moreover it is possible to obtain the Shottky correction to the zero-field saturated emission. Cell currents reported here are obtained by extrapolating the $\log i$ is $V^{\frac{1}{2}}$ curves to zero volts, yielding the saturated current density $i_{0}$ for zero field.

\section{TEMPERATURE MEASUREMENTS}

While absolute currents can be measured with the desired precision, the accuracy of the emitter temperature measurement is severely limited since the radiative emissivities of the carbides are not well established. Surface temperatures are measured by viewing the emitting surface directly with a pyrometer. We have

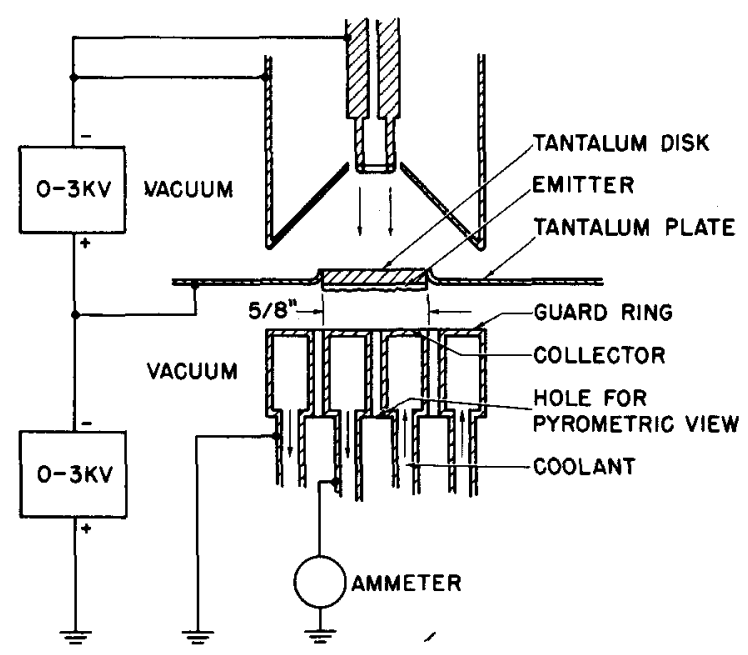

Fig. 1. A diagram of the apparatus for emission studies, showing the electron-gun heater, the emitter plate, and the guarded collector. 


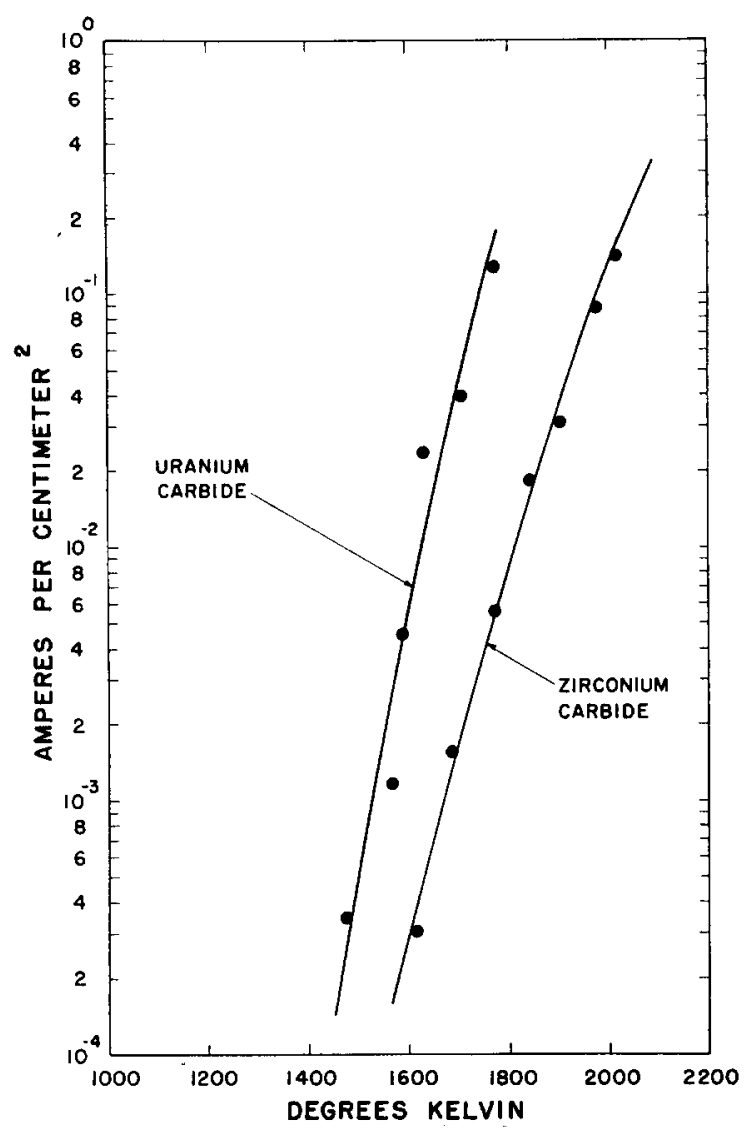

FIG. 2. Observed saturated current densities from $\mathrm{ZrC}$ and $\mathrm{UC}$ as a function of absolute temperature. Points represent observed data. Curves portray the Richardson equation using values of $A$ and $\phi$ quoted in Table $I$.

made crude observations of the $0.65-\mu$ emissivities by perforating and cracking the samples so that hohlraum temperatures can be compared with surface temperatures. For the UC samples, the hole and surface temperatures are so nearly the same that they escape accurate differentiation. Differences are of the order of $20^{\circ} \mathrm{C}$ at $1500^{\circ} \mathrm{C}$. We assign a value of 0.9 to the UC emissivity at $0.65 \mu$. At such high values of emissivity, the temperature corrections are very small, and we believe no significant error is caused by this somewhat arbitrary assignment. The emissivity of $\mathrm{ZrC}$ is evaluated in a similar manner, and we assign a value to $0.65-\mu$ emissivity of 0.7 . $\mathrm{ZrC}$ : $\mathrm{UC}$ is evidently intermediate between $\mathrm{UC}$ and $\mathrm{ZrC}$, and we have assigned it an emissivity value of 0.8 . These latter two assignments correspond to more significant temperature shifts, of the order of $50^{\circ} \mathrm{C}$. Here again, we do not believe these assignments will materially alter the conclusions of this article. However, improved measurements of carbide emission should include either thermocouple temperature measurements or more extensive measurements of the radiative emissivities of the carbides.

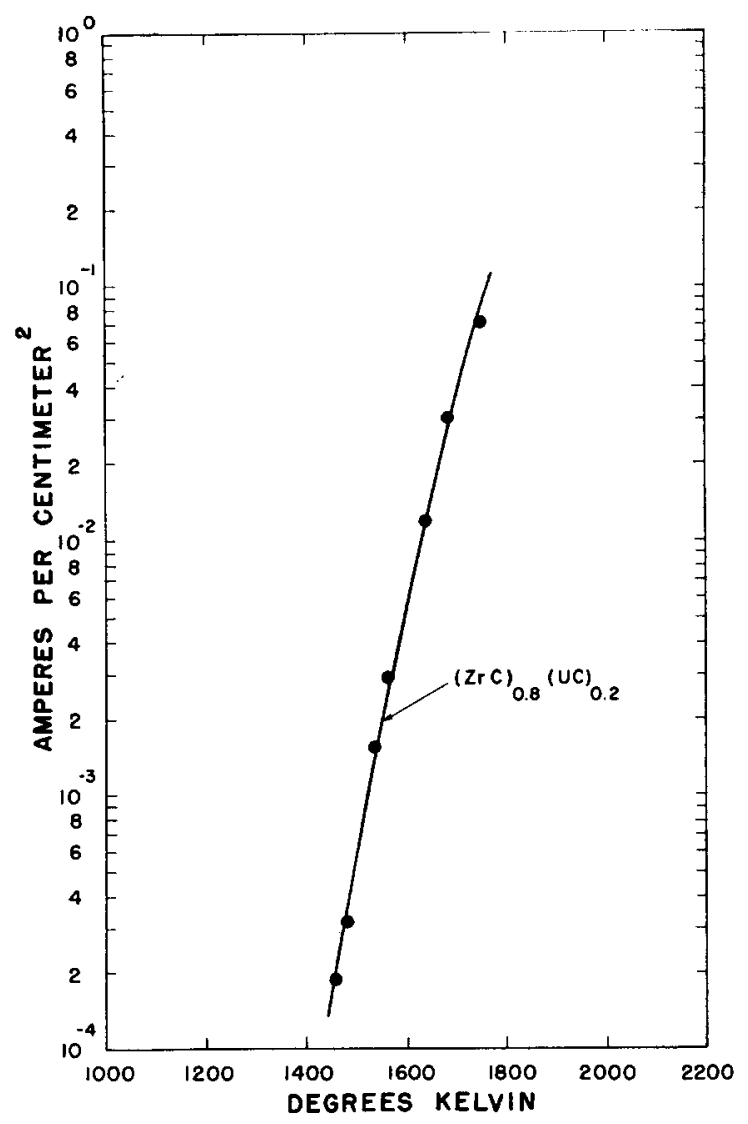

FIG. 3. Observed saturated current densities from $\mathrm{ZrC}_{0.8} \mathrm{UC}_{0.2}$ as a function of absolute temperature. Points represent observed data. Curves portray the Richardson equation using values of $A$ and $\phi$ quoted in Table I.

\section{DATA}

In Fig. 2 are shown the observed saturated current densities versus the observed absolute emitter temperature for $\mathrm{ZrC}$ and $\mathrm{UC}$. The actual emitter area was $2 \mathrm{~cm}^{2}$. The most striking feature of the UC curve is that, while the emission is very high compared with that of pure metals, the $\log i_{0}$ vs $T$ slope is so great that it is nearly impossible to assign emission parameters with any accuracy at all. It will be noted that the 80 atomic percent $\mathrm{ZrC}, 20$ atomic percent $\mathrm{UC}$ mixture gives very closely the same emission as pure UC. These data are shown separately in Fig. 3. A slight change in slope between the $\mathrm{UC}$ and $\mathrm{ZrC}: \mathrm{UC}$ emission curves does change the emission parameters considerably, but this is because we are in a range where the values of the emission parameters are very sensitive to such a change.

While there is no proof that these emitters can be characterized by a Richardson emission law, the data can be fitted by this law:

$$
i_{0}=A T^{2} e^{-e \phi / K T} ;
$$

$T=$ absolute temperature Kelvin, $e=$ electronic charge coulombs, $K=$ Boltzmann constant ergs per degree Kelvin per particle, $\phi=$ work function in volts, for 
TABLE I. The $A$ and $\phi$ parameters in the Richardson equation for the observed thermionic emission from $\mathrm{ZrC}, \mathrm{UC}$, and the $\mathrm{ZrC}: \mathrm{UC}$ mixture

\begin{tabular}{lcl} 
Compound & $A\left[\mathrm{amp} / \mathrm{cm}^{2}\left({ }^{\circ} \mathrm{K}\right)^{2}\right]$ & (volts) \\
\hline $\mathrm{ZrC}$ & 134 & 3.8 \\
$\mathrm{UC}$ & $7.3 \times 10^{5}$ & 4.57 \\
$\mathrm{ZrC}_{0.8} \mathrm{UC}_{0.2}$ & $6.6 \times 10^{4}$ & 4.3 \\
\hline
\end{tabular}

illustrative purposes. The results of this fitting are given in Table $\mathrm{I}$. The values of $A$ and $\phi$ for $\mathrm{ZrC}$ appear to conform with typical metallic values. However, the extremely high values of $A$ for $\mathrm{UC}$ and the $\mathrm{ZrC}$ : UC mixture always occur, and they have been observed in several trials with different samples. However, we doubt that our assignment of such high values of $A$ has any significance beyond the empirical fitting of a twoparameter curve to the set of data. For example, the data can be quite easily fitted with a temperature-dependent work function and an $A$ value of $60 \mathrm{amp} / \mathrm{cm}^{2}\left({ }^{\circ} \mathrm{K}\right)^{2}$. Further investigation would be required before anything more could be said about the nature of the emission and why it is so high compared with metallic values. We wish only to assert that the current-temperature values portrayed in Figs. 1 and 2 are reproducible data, within the limitations mentioned in the description of the experiment.

Reference has been made to a comparison of the carbide emission versus the emission of pure metals. We quote the emission values for $\mathrm{ZrC}$ : $\mathrm{UC}$ and for tantalum metal, measured in the same apparatus at $1800^{\circ} \mathrm{K}$. The current density from $\mathrm{ZrC}$ : UC is $1.6 \times 10^{-1}$ $\mathrm{amp} / \mathrm{cm}^{2}$. The current density from tantalum is $1 \times 10^{-4}$ $\mathrm{amp} / \mathrm{cm}^{2}$. The ratio of saturated current densities at $1800^{\circ} \mathrm{K}$ is 1600 .

\section{OTHER PROPERTIES}

Pure UC has an unsatisfactory feature in regard to its use as a structural element. Upon thermal cycling, some fractures in the $\mathrm{UC}$ body are always found. By contrast, $\mathrm{ZrC}$ is much more resistant to thermal shock and thermal cycling. Fractures in $\mathrm{ZrC}$ samples have never been observed, even though it has been rapidly cycled from room temperature to $2400^{\circ} \mathrm{C}$ and return many times. The same resistance to shock and cycling is observed for the $\mathrm{ZrC}$ : UC mixtures. Thus, since the mixture is as good an emitter as pure UC, in this temperature range, it is much more desirable for practical use because of the strength of the mixture.

$\mathrm{ZrC}$ has a much higher melting point, $3500^{\circ} \mathrm{C}$, than $\mathrm{UC}, 2450^{\circ} \mathrm{C}$. Laboratory tests have shown that the
$\mathrm{ZrC}: \mathrm{UC}$ mixture can probably be operated at higher temperatures than UC. For this reason too, the mixture is more desirable than pure UC.

Experiments have not yet been done on the effect of varying the percent composition of $\mathrm{ZrC}$ and $\mathrm{UC}$. A clue to the possible results is provided, however, by our experience in melting $\mathrm{UC}$ in the presence of a hot tungsten filament. In a period of a few minutes, the tungsten emission changed substantially by as much as 3 times, at a given operating temperature. This observation is only qualitative in nature, but it suggests that it would be worthwhile to study the effect of UC in trace amounts on metallic emission properties.

No activation schedule is used for the emission properties quoted here, nor is any special surface cleaning performed before the carbide emitter is introduced into vacuum. Flashing to higher temperatures does not affect the emission. After long exposure to laboratory air, the emission is the same as after continuous duty in vacuum. In a fast vacuum system the emitter may be used wlthout delay. For use in a static system the arc-fused carbides must be thoroughly outgassed. Outgassing is achieved at a pressure of $1 \mu \mathrm{Hg}$. At higher pressures the surface can be oxidized upon heating, and the good emission properties are completely destroyed.

The uranium carbide compound contains a fissionable element. One of the objectives of this research program is to design an electric power-producing reactor utilizing the principle of direct, thermoelectric, heat-to-electric energy conversion. It is somewhat remarkable that two material properties important to such a design, fissionability and superior electron emission characteristics, are embodied in a single compound. We believe this may be a fact of some importance to future reactor technology.

A remark should be made about the discrepancy between our results and those of Goldwater and Haddad. They report for $\mathrm{ZrC}$ emission parameters of $A=0.3 \mathrm{amp} / \mathrm{cm}^{2}{ }^{\circ} \mathrm{K}^{2}$ and $\phi=2.1 \mathrm{v}$. The difference between the two experimental results may be due to the relative purity of samples and the physical form of the emitter. They used $\mathrm{ZrC}$ powder electrophoretically deposited on a carbon rod.

\section{ACKNOWLEDGMENTS}

The authors wish to thank Dr. Melvin G. Bowman for his support in the development of carbide metallurgy, without which this work would have been impossible. We also thank Mr. George F. Erickson for his invaluable assistance in the development and construction of the experimental equipment. 